\title{
VALIDAÇÃO DE INSTRUMENTO DE AVALIAÇÃO DAS CONDIÇÕES DE SAÚDE BUCAL DE IDOSOS INSTITUCIONALIZADOS
}

\author{
Validity of an oral health acessment tool for institutionalized elderly people \\ Validación de instrumento de evaluación de las condiciones de salud oral de ancianos \\ institucionalizados.
}

Karoline Zimermann ${ }^{3}$

\begin{abstract}
RESUMO
Objetivou-se trazer para a realidade brasileira, via tradução e validação, o instrumento Oral Health Assessment Tool, de Chalmers et al. (2005), que propõe instrumentalizar profissionais da enfermagem a averiguarem as condições de saúde bucal de idosos institucionalizados e, em sequência, definir a necessidade de cuidados diários e de encaminhamento para realização de procedimentos odontológicos específicos. 0 instrumento, em inglês, foi traduzido para a língua portuguesa. Seguiram-se as etapas de tradução reversa e análise por comitê de 10 experts convidados a validar o instrumento segundo as equivalências semântica, idiomática, cultural e conceitual. Na sequência, o instrumento foi submetido à análise por 21 profissionais de enfermagem de uma instituição de longa permanência, para que manifestassem suas opiniões sobre conteúdo, apresentação, leitura/clareza e aplicação prática do instrumento. Apresenta-se aos profissionais de enfermagem uma ferramenta de diagnóstico e encaminhamento de idosos com relação às demandas de saúde bucal em instituições de longa permanência.
\end{abstract}

Palavras-chave: Estudos de Validação. Saúde do Idoso Institucionalizado. Saúde Bucal.

\begin{abstract}
This study aimed to bring for the Brazilian reality, through translation and validation, the Oral Health Assessment Tool, of Chalmers et al. (2005), which propose a tool for nursing professionals to evaluate the oral health conditions of institutionalized elderly people, followed by the definition of the daily care needs and the direction for accomplishment of specific dental procedures. The instrument, in English, was translated to the Portuguese language. The stages of reverse/back translation and analysis were followed by a committee of 10 experts invited to validate the instrument according to the semantic, idiomatic, cultural and conceptual equivalences. In the sequence, the instrument was submitted to the analysis by 21 nursing professionals of a long term care institution to manifest their opinions on content, presentation, reading/clarity and practical application of the instrument. It is presented to the nursing professionals a diagnostic and direction tool with relationship to the oral health of the elderly demands in long term care institutions
\end{abstract}

Keywords: Validation Studies. Health of Institutionalized Elderly. Oral Health

\section{Resumen}

Se objetivó traer para la realidad brasileña, a través de la traducción y validación, el instrumento Oral Health Assessment Tool, de Chalmers et al. (2005), que propone instrumentalizar el profesional de enfermería a evaluar las condiciones de la salud bucodental de las personas mayores institucionalizadas y, en la sucesión, definir la necesidad de cuidados diarios y de dirección para el logro de procedimientos odontológicos específicos. El instrumento, en inglés, fue traducido para el idioma portugués. Fueron seguidas las fases de traducción inversa y análisis por comité de 10 expertos invitados para validar el instrumento según equivalencia semántica, idiomática, cultural y conceptual. En la sucesión, el instrumento fue sometido al análisis por 21 profesionales de enfermería de una institución de larga estancia, para que manifestasen sus opiniones cuanto al contenido, presentación, lectura/clareza y aplicación práctica del instrumento. Se presenta a los profesionales de enfermería una herramienta de diagnóstico y dirección de personas mayores con relación a las demandas de salud bucodental en las instituciones de larga estancia.

Palabras clave: Estudios de Validación. Salud del Anciano Institucionalizado. Salud Oral.

'Doutora em Enfermagem - Professora do Programa de Pós-graduação em Enfermagem da UFSC - Florianópolis- SC. Brasil. E-mail: lucia@nfr.ufsc.br, ${ }^{2}$ Doutora em Enfermagem - Professora do Departamento de Odontologia da UFSC - Florianópolis- SC. Brasil. E-mail: alfm@terra.com.br ,'Bolsista PIBIC - Aluna do curso de Odontologia da UFSC - Florianópolis- SC. Brasil. E-mail: karolinezimermann@hotmail.com. 


\section{INTRODUÇÃO}

À medida que as pessoas atingem as últimas décadas de vida, as necessidades de cuidados permanentes aumentam ${ }^{1}$, inclusive em relação aos cuidados dirigidos à saúde bucal.

Com o avançar da idade, há uma tendência de declínio no nível de higiene bucal e um aumento da incidência de doenças bucais. A diminuição da capacidade motora, a baixa autoestima, a falta de estímulo para a realização da higiene bucal, a incapacidade de realizar sua própria higiene devido a doenças crônico-degenerativas, o comprometimento da visão, audição e a perda da habilidade cognitiva são fatores que, isolada ou cumulativamente, contribuem para o aumento do risco das pessoas idosas desenvolverem enfermidades bucais. Tem-se observado que o comprometimento da saúde bucal do idoso é fator de isolamento, depressão e causa de outras morbidades². 0 cuidado à saúde bucal implica, nas esferas individual e coletiva, um processo dinâmico e contínuo de reconhecimento da influência das condições bucais nas diversas dimensões do viver humano e a consequente tomada responsável de decisões e ações dirigidas à promoção da saúde, com vistas a proteger a vida. 0 cuidado à saúde bucal, assim, é uma construção cotidiana que pressupõe uma visão integral do ser humano e das suas relações com a sociedade e com o meio ambiente ${ }^{3}$.

Este estudo pretendeu dar suporte a um projeto maior, multicêntrico, intitulado Instituições de Longa Permanência para Idosos (ILPI) no Brasil: Tipologia e proposta de modelo básico de assistência multidimensional, financiado pelo CNPq / MS-SCTIE-DECIT, processo 555079/2006-6. Em se tratando de uma proposta de modelo multidimensional, incorporou-se o cuidado à saúde bucal, entendido como uma vertente do cuidado integral que os idosos recebem nestas instituições e como um dos aspectos a serem trabalhados nesse modelo básico de assistência. Desse modo, o estudo, a padronização e a validação de instrumentos a serem incluídos na implementação da avaliação diagnóstica multidimensional desse modelo seguem a mesma linha de outros instrumentos que serão utilizados na avaliação das condições de vida e saúde dos idosos residentes como a Caderneta do Idoso do Ministério de Saúde, o índice de avaliação da capacidade funcional física da American Alliance for Health, Physical Education, Recreation and Dance (AAHPERD), as atividades físicas da vida diária pelo Índice de Katz, entre outros.

0 objetivo deste estudo é traduzir para o idioma português o instrumento Oral Health Assessment Tool, para avaliação, por pessoal de enfermagem, das condições de saúde bucal de idosos institucionalizados, bem como submeter os instrumentos traduzidos à validação semântica e de conteúdo.

\section{Revisão da literatura}

Dados internacionais apontam que a população idosa tende a apresentar uma precária condição de saúde bucal, não exclusivamente, mas em grande parte por reflexo de deficiências no cuidado à saúde bucal ao longo da vida. Os idosos que apresentam algum grau de dependência ou têm sua autonomia comprometida apresentam piores condições de higiene bucal ${ }^{4,5}$.

Estudos realizados em ILPI revelam que, neste contexto, o adequado cuidado com a saúde bucal não tem sido contemplado e costumeiramente observam-se flagrantes omissões ${ }^{6,7}$. No Brasil, o mais recente levantamento epidemiológico de saúde bucal de abrangência nacional, o SBBRASIL, divulgado em 2003, revelou, para idosos de 65 a 79 anos, um índice CPOD (resultado da soma de dentes permanentes acometidos, restaurados ou extraídos por cárie em um indivíduo) de 27,79 , em sua maior parte composto pelo componente "perdido" (93\%), seguido do "cariado" $(1,23 \%)$ e do "obturado" (0,7\%); 45,4\% dos elementos dentais necessitavam de exodontia. Quanto ao uso de próteses dentárias, 66,54\% e 30,94\% dos idosos possuíam-nas na arcada superior e inferior, respectivamente. Quando questionados sobre como classificavam a sua saúde bucal, 50,25\% dos idosos consideravam-na ótima ou boa 8 .

A literatura nacional confirma essa realidade ao apresentar estudos realizados em várias regiões do país. Independentemente das condições de vida e saúde geral dos idosos pesquisados (institucionalizados, participantes de grupos de convivência ou visitados em seus domicílios), eles apresentaram altos índices de edentulismo, cárie e doença periodontal, além da elevada necessidade de próteses. Esse quadro parece refletir uma organização dos serviços de atenção à saúde bucal do adulto e do idoso, baseada em um modelo de intervenção com ênfase na eliminação de sintomatologia dolorosa, $a^{9,10}$

No Brasil, não há normas específicas referentes ao cuidado à saúde bucal em instituições. Têm-se observado, geralmente, ausência de protocolos de procedimentos, falta de programação de atenção especializada e ausência de programas de orientação e capacitação dos cuidadores profissionais ou leigos ${ }^{11}$.

Os fatores que influenciam cuidadores na provisão do cuidado à saúde bucal em instituições para idosos foram estudados em lowa, EUA. Foram entrevistados 488 cuidadores com média de idade de 38 anos. Os cuidadores relataram realizar escovação dental $(86,3 \%)$ e limpeza das próteses totais $(89,6 \%)$, porém despendiam pouco tempo, menos de três minutos por residente. Outros cuidados, como bochechos com soluções com e sem flúor e limpeza interdental, também foram relatados em menores proporções. Foram consideradas causas que impediam a provisão adequada de cuidados odontológicos a falta de tempo e de pessoal, dificuldades físicas e de comportamento dos idosos e a falta de um programa de educação em saúde bucal específico para cuidadores de idosos. Os autores apresentaram também um diagrama-modelo dos fatores influentes agrupando em quatro grandes segmentos: características organizacionais da instituição, formação profissional do cuidador, características pessoais do cuidador, características dos idosos da instituição ${ }^{12}$. 
0 cuidado à saúde bucal, quando realizado por terceiros, é praticado por profissionais de áreas da saúde, ou seja, por pessoas que em algum momento e em diferentes níveis de formação obtiveram conhecimentos acadêmicos formais para desenvolvimento de habilidades específicas de cuidado em suas esferas de competência. Esta formação quando analisada pelo ângulo dos profissionais de enfermagem demonstra-se incompleta, não atendendo às necessidades cotidianas de cuidado à saúde bucal apresentadas pelos idosos. Interessante verificar que os conhecimentos utilizados como base para fundamentar suas práticas de cuidado à saúde bucal são mais de caráter empírico, popular, do que de caráter técnicoprofissional, e têm origem na própria família e nos meios de comunicação, mais do que em espaços formais e acadêmicos, ou mesmo fruto de treinamento e capacitação específicos. Seguindo essa direção, também os profissionais da Odontologia ressentem-se de não possuírem sólidos conhecimentos acadêmicos sobre o contingente idoso e os cuidados a sua saúde bucal. Assim, aqui a contradição se estabelece ante a intervenção necessária do profissional e a sua sujeição à falta de conhecimentos específicos proclamados por evidências científicas, fato que diminui seu poder de ação e o valor dado ao cuidado à saúde bucal do idoso ${ }^{3}$.

Em 2005, estudo apontou a necessidade do uso de instrumentos como ferramentas para rastreamento (screening), a serem utilizadas por cuidadores, juntamente à idosos que possuíssem algum grau de comprometimento cognitivo em ILPI. Àquela época afirmavam ser conveniente 0 desenvolvimento e validação de tais instrumentos, bem como a aplicação de ações educativo-preventivas e de estratégias comportamentais e de comunicação específicas para essa população ${ }^{13}$.

Também em 2005, foi publicada uma proposta de instrumento para avaliar as condições de saúde e higiene bucal, dentro do conjunto de ações desenvolvidas pelo Best Pratices Oral Health Model for Australian Residencial Care Study. 0 instrumento Oral Health Assessment Tool (OHAT) tem como objetivo fornecer aos cuidadores de idosos em ILPI um instrumento simples, com oito categorias de análise para avaliar a saúde bucal dos residentes, inclusive aqueles com comprometimento cognitivo. 0 instrumento foi validado, apresentando boa reprodutibilidade e confiabilidade ${ }^{14}$.

Os protocolos de higiene bucal para idosos fragilizados e funcionalmente dependentes devem prever a atuação da equipe de profissionais da saúde. A avaliação das condições de saúde geral e bucal dos idosos pelos cuidadores é o primeiro passo na definição dos procedimentos em protocolos. A higiene bucal diária de dentes e próteses, das mucosas bucais e a hidratação oral fazem parte do rol de procedimentos que serão individualmente prescritos de acordo com as características e necessidades dos idosos. A participação do cirurgiãodentista, como colaborador no processo, a continuidade das ações e o treinamento dos cuidadores são outros fatores importantes para o sucesso do protocolo ${ }^{15}$.

Uma revisão sistemática da literatura buscou identificar os instrumentos elaborados para avaliar as condições de saúde bucal de idosos e outros aspectos relacionados a serem utilizados por profissionais de enfermagem e cuidadores em geral no âmbito das ILPI. Poucos foram os instrumentos citados na literatura que fossem validados e confiáveis, principalmente no que diz respeito à possibilidade de aplicação em diferentes graus de comprometimento cognitivo dos idosos. Três instrumentos são citados: o Brief Oral Health Status Examination e outros dois, menos completos, o Index of Activities of Daily Oral Hygiene e o Mucosal Plaque Score. Os autores sugerem que a prática de exames bucais deveria ser corrente, realizada pelos profissionais de enfermagem e cuidadores capacitados, no intuito de monitorar as condições de saúde bucal dos idosos, avaliar a higiene bucal e, em casos de necessidade de atendimento especializado, os cuidadores recorrerem ao cirurgião-dentista ${ }^{13}$.

Outros pesquisadores, preocupados com a identificação rápida e simplificada de necessidades de cuidado à saúde bucal de idosos, elaboraram estudo para desenvolver uma questão única que, formulada por cuidadores, pudesse servir como ferramenta de rastreamento. Foi avaliada a questão "Do you have regular dental checkups?" como fator para decisão se o idoso necessita de uma avaliação da sua saúde bucal e posterior referência para atendimento. A resposta negativa à questão foi considerada preditor de uma pobre saúde bucal e, consequentemente, de necessidades de cuidado. Foi realizada a avaliação das condições de saúde bucal por meio de três indicadores validados, próprios para serem aplicados por pessoal de enfermagem. Os idosos que não realizavam checkups com regularidade possuíam os piores escores de saúde bucal nos três indicadores. 0 item único "Do you have regular dental checkups?" apresentou-se válido para classificar idosos dentados que possuam boa saúde bucal e identificar aqueles que necessitam avaliação ou atendimento futuro. Para idosos edêntulos a questão se mostrou menos efetiva ${ }^{16}$.

A saúde bucal de idosos residentes em instituições é bastante precária devido ao acesso limitado aos serviços odontológicos e à inexistência de uma rotina diária de higiene bucal. Porém somente 0 acesso ao cirurgião-dentista não é suficiente para solucionar os problemas de saúde bucal em ILPI ${ }^{17}$. 0 fornecimento da atenção e assistência odontológicas para idosos institucionalizados apresenta-se como um enorme desafio. Estes desafios vão desde a existência de pessoal treinado, disponibilidade de equipamentos, recursos para assistência e as condições de saúde geral e bucal dos idosos ${ }^{18}$. 
A saúde bucal é componente inseparável do sistema de saúde corporal, capaz de afetar, além do bem-estar físico, também o bem-estar psicossocial das pessoas. Assim, defende-se que o cuidado à saúde bucal também deve e necessita ser componente inseparável e articulado de qualquer sistema de atenção integral à saúde do idoso, e particularmente dos idosos institucionalizados. A organização do cuidado à saúde bucal no âmbito das ILPI deve estar integrada às demais atividades assistenciais de saúde, não perdendo a perspectiva da necessidade de ações mais amplas, como as de educação em saúde e preventivas. Para a elaboração deste protocolo de cuidado à saúde bucal, padronizado em relação à instituição, mas flexível no que diz respeito às necessidades individuais de cada idoso residente, torna-se imperativo o conhecimento das condições de saúde bucal do idoso, a presença de próteses dentárias, necessidade de tratamento imediata, a rotina de higiene bucal realizada diariamente, a capacidade física e cognitiva deste para realizar sua própria higiene bucal, a necessidade de auxílio para tal, bem como o rol de procedimentos necessários para que mantenha uma higiene bucal satisfatória, que permita resgatar e manter sua saúde bucal. Desse modo, a coleta destas informações e registro desses dados demanda um instrumento testado, adequado à realidade sociocultural das instituições, dos profissionais de saúde e também dos idosos³.

\section{MÉTODO}

\section{Histórico e descrição do instrumento}

Em 2004, foi apresentado um protocolo de higiene bucal para idosos funcionalmente dependentes e com comprometimento cognitivo, incluindo a proposta de instrumento para avaliar as condições de saúde e higiene bucal, a ser aplicado por seus cuidadores. Seguem seus estudos com a apresentação da revisão sistemática sobre instrumentos elaborados para avaliar as condições de saúde bucal de idosos e outros aspectos relacionados a serem utilizados por profissionais de enfermagem e cuidadores em geral no âmbito das ILPI. Em 2005, o instrumento foi validado e denominado Oral Health Assessment Tool (OHAT), ${ }^{14}$ com oito categorias de análise (Lábios, Língua, Gengivas e tecidos, Saliva, Dentes naturais, Dentaduras, Higiene bucal e Dor de dente). 0 OHAT foi testado em 21 ILPI australianas, sendo reaplicado aos três e seis meses para testar a reprodutibilidade intra e intercuidadores. Participaram do estudo 455 residentes. A confiabilidade intracuidador do OHAT alcançou as seguintes porcentagens segundo as categorias: 74,4 para higiene bucal; 93,9 para presença de dor dental; o coeficiente Kappa foi moderado $(0,51-0,60)$ para lábios, saliva, higiene bucal, e obteve concordância substancial $(0,61-0,80)$ para as outras categorias. A confiabilidade intercuidador atingiu uma porcentagem de 72,6 para higiene bucal até 92,6 para dor dental. 0 coeficiente Kappa foi moderado $(0,48-0,60)$ para lábios, língua, gengiva, saliva e higiene bucal, e, para outras categorias, foi de $0,61-0,80$. Os coeficientes de correlação intraclasse para os escores totais do OHAT foram 0,78 para intracuidadores e 0,74 para intercuidadores. Como conclusão o Oral Health Assessment Tool foi considerado válido como instrumento de rastreamento (screening) em ILPI para avaliar as condições de saúde bucal dos idosos, inclusive aqueles com comprometimento cognitivo. Ou seja, a Oral Health Assessment Tool (OHAT) tem como objetivo avaliar as condições de saúde bucal do idoso, dependendo do escore alcançado determina a necessidade de encaminhamento para tratamento odontológico. Além da identificação do idoso, esse instrumento avalia oito itens: lábios, língua, gengivas e tecidos moles, saliva, presença de dentes naturais, presença de dentaduras, higiene bucal e dor. Para cada item o cuidador deve atribuir um escore de 0 a 2, em função das condições apresentadas pelo idoso. 0 escore final é a soma dos escores que pode então variar de 0 (muito saudável) a 16 (muito doente).

\section{Tradução do Instrumento}

Inicialmente venceram-se os trabalhos de tradução, em dois momentos. 0 primeiro consistiu na tradução do instrumento da língua inglesa para a portuguesa. Os instrumentos foram entregues a dois tradutores com experiência em textos na área da saúde, que foram devidamente informados sobre os objetivos do trabalho. Os resultados das traduções apresentaram-se semelhantes, com poucas divergências, as quais foram eliminadas na etapa seguinte.

Estabelecida a versão em português, submeteuse, em um segundo momento, a um terceiro tradutor, que produziu a tradução reversa (back translation) constatando, assim, a fidelidade do documento traduzido. 0 instrumento em português passou a ser denominado Instrumento de avaliação da saúde bucal para a triagem odontológica.

\section{Etapas da Validação}

A validação do instrumento traduzido foi desmembrada em duas etapas. Na primeira etapa houve a submissão dos instrumentos a experts da área da saúde com intuito de produzir uma versão final, consolidada, da tradução do instrumento. Na segunda etapa, o instrumento, já definido pelos experts, foi analisado e aprovado por profissionais da área da enfermagem.

- Validação pelo painel de experts:

0 s instrumentos foram enviados a 10 experts da área da saúde, docentes de universidades federais, atuantes na área de geriatria e gerontologia, com experiência na área de cuidado ao idoso institucionalizado. Os instrumentos (original e 
traduzido) foram enviados individualmente, via e-mail, anexos a uma carta-convite explicativa que descrevia os intuitos do projeto e as orientações para a realização da validação. Os experts modificaram o instrumento, acrescentando, eliminando ou alterando os conteúdos que lhes pareciam necessários. A tarefa de avaliação levou em consideração os preceitos de:

- Equivalência semântica: avaliação da equivalência gramatical e de vocabulário. As palavras que não possuíssem uma tradução literal com significado semelhante foram traduzidas para os termos em português que apresentavam equivalência de significado.

— Equivalência idiomática: tradução de certas expressões idiomáticas que não pode ser feita de forma literal, devendo equivaler no seu sentido.

- Equivalência experimental ou cultural: coerência entre os termos utilizados e as experiências vividas pela população à qual se destina, dentro do seu contexto cultural. A equivalência experimental ou cultural foi verificada por meio de entrevista com os profissionais de Enfermagem, analisando qualitativamente as respostas.

- Equivalência conceitual: muitos itens utilizados nos instrumentos podem equivaler-se semanticamente, sem, contudo, apresentar equivalência de conceito. Os termos podem representar conceitos diferentes em contextos específicos. A equivalência conceitual foi revisada na etapa em que a tradução é revista pelo painel. A tradução foi avaliada quanto à clareza para o pessoal de enfermagem, analisando sua compreensão individualmente.

Foram consideradas as avaliações com $90 \%$ de concordância entre os participantes do painel.

- Validação pelos profissionais de enfermagem:

Participaram desta etapa 21 profissionais de enfermagem, entre enfermeiros, técnicos e auxiliares de enfermagem de uma ILPI da região da Grande Florianópolis (SC). Como critério de inclusão definiuse convidar: funcionário da ILPI em questão, com formação em enfermagem, estar envolvido direta ou indiretamente no cuidado à saúde bucal dos idosos, e voluntariar-se em participar do estudo.

Foi entregue, por escrito e individualmente, 0 instrumento agora já revisto segundo a avaliação do painel de experts, acompanhado de guia instrucional para o seu uso. Foi produzida uma teleaula para auxiliar na compreensão dos profissionais de enfermagem sobre o objetivo e utilização do instrumento. Esta aula, em forma de vídeo explicativo, foi apresentada a todos os 21 participantes e demonstra, de forma didática, como deve ser efetuado o exame bucal e como preencher corretamente 0 instrumento.
Após a exposição da teleaula, foram explicitadas as tarefas de validação a serem realizadas. Foi solicitada aos profissionais de enfermagem a análise de itens referentes ao conteúdo, forma de apresentação, facilidade de leitura, clareza e compreensão e aplicação prática. Para análise da viabilidade da aplicação dos instrumentos, a tarefa dos participantes consistiu em: a) receber as orientações sobre o uso do instrumento via teleaula, b) apreciar o instrumento e c) responder, individualmente e por escrito, a um formulário composto por 12 assertivas, as quais tinham como opção de resposta os itens: Não Concordo Fortemente, Não Concordo, Concordo e Concordo Fortemente, e mais duas questões abertas: o que seria necessário para aprender a utilizar o instrumento? E quais as barreiras que poderiam dificultar a utilização do instrumento na sua instituição?

A pesquisa foi conduzida dentro dos preceitos da ética na pesquisa com seres humanos. Foi submetida ao Comitê de Ética em Pesquisa em Seres Humanos da Universidade Federal de Santa Catarina, de acordo com a Resolução CNS 196/96 e aprovada segundo parecer no. 107/08, em 30 de junho de 2008. Os participantes foram solicitados a manifestar seu consentimento por meio da assinatura do Termo de Consentimento Livre e Esclarecido

\section{RESULTADOS E DISCUSSÃO}

Os experts modificaram algumas expressões que não possuíam equivalência em português, como "denture cleaner", adaptado como "escovas para dentadura". Sugeriram também a modificação da expressão "denture", que havia sido traduzida como prótese em geral (parcial ou total), mas que, na verdade, corresponde a prótese exclusivamente total. Além das correções de ortografia e gramática e a substituição de sinônimos que se adequavam melhor ao contexto brasileiro, a necessidade de treinamento dos profissionais da área da enfermagem também foi salientada nesta avaliação. Outro aspecto muito enfatizado pelos experts foi a disposição/formatação do texto do instrumento, o qual foi reorganizado em tópicos específicos, facilitando assim a leitura e compreensão.

Após a avaliação minuciosa de todas as sugestões, procedeu-se as modificações indicadas pelo comitê de experts, e produziu-se a formatação do "Instrumento de avaliação da saúde bucal para a triagem odontológica" (Quadro 1), agora com a versão final em português, a qual foi, na sequência, apresentada para a análise dos profissionais de enfermagem. 
Quadro 1 - Instrumento de Avaliação da Saúde Bucal para a Triagem Odontológica

\begin{tabular}{|c|c|c|c|c|}
\hline \multicolumn{5}{|c|}{$\begin{array}{l}\text { Paciente: } \\
\text { por: } \\
\text { Pontuação: a pontuação final resulta da soma dos pontos das oito categorias e varia entre zero (muito sa udável) e } 16 \text { (muito doente). } \\
\text { Uma vez que os pontos cumulativos são importantes para a avaliação da sa úde bucal, a pontuação de cada item precisa ser } \\
\text { considerada individualmente. Os sintomas sublinhados requer em a tença imediata. } \\
\text { * Se qualquer categoria tiver uma pontua ção de } 1 \text { ou } 2 \text {, providencie para que o paciente seja examinado por um dentista. } \\
\text { * A presença de qualquer um dos aspectos mencionados nas categorias determina o escore nela indica do. }\end{array}$} \\
\hline 1) Categor ia & $0=$ saudá vel & $1=$ presença de altera çõe s* $^{*}$ & 2 = não saudá vel* & $\begin{array}{c}\text { Pontuação } \\
\text { por } \\
\text { categoria }\end{array}$ \\
\hline 2) Lábios & $\begin{array}{l}\text { Lisos, rosados, } \\
\text { úmidos }\end{array}$ & $\begin{array}{ll}\text { - } & \text { Rachados } \\
\text { - } & \text { Averm elhados nas } \\
\text { - } & \text { com is suras (cantos) }\end{array}$ & 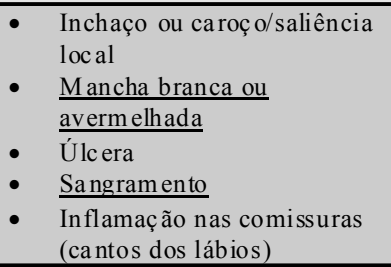 & \\
\hline $\begin{array}{l}\text { 4) Gengivas e } \\
\text { te cidos }\end{array}$ & $\begin{array}{l}\text { Rosados, úmidos, } \\
\text { macios, sem } \\
\text { sangramento }\end{array}$ & $\begin{array}{ll}\text { - } & \text { Avermelhados } \\
\text { - } & \text { Secos } \\
\text { - } & \text { Inchados } \\
\text { - } & \text { B rilhosos } \\
\text { - Áspe ros/rugoso } \\
\text { - } & \text { Mancha ou úlce ra } \\
& \text { embaixo das } \\
& \text { dentaduras } \\
\end{array}$ & $\begin{array}{l}\text { - } \\
\text { - } \frac{\text { avermelhadas }}{\text { Vermelhidão generaliza da }} \\
\text { - Gengivas inchadas } \\
\text { - Sangramento } \\
\text { Úlc eras }\end{array}$ & \\
\hline $\begin{array}{l}\text { 7) Dentaduras } \\
\text { Sim ou Não }\end{array}$ & $\begin{array}{l}\text { Nenhuma área ou } \\
\text { dente que bra do. } \\
\text { Denta duras } \\
\text { utiliza das em } \\
\text { ambas as arca das } \\
\text { continuamente } \\
\text { durante o dia }\end{array}$ & $\begin{array}{ll}\text { - } & 1 \text { área ou } 1 \text { dente } \\
\text { danific ado } \\
\text { Dentaduras utilizadas } \\
\text { por apenas } 1 \text { a } 2 \text { h ao } \\
\text { dia Dentaduras } \\
\text { soltas/froxas } \\
\text { Usa somente uma } \\
\text { dentadura (superior ou } \\
\text { inferior) }\end{array}$ & $\begin{array}{l}\text { Mais de } 1 \text { área ou mais de } 1 \\
\text { dente danificado } \\
\text { - } \frac{\text { Falta de dentadura ou }}{\text { dentadura não utilizada }} \\
\text { Precisa de adesivo para } \\
\text { denta dura }\end{array}$ & \\
\hline 8) Higiene bucal & $\begin{array}{l}\text { Boca limpa; Sem } \\
\text { resíduos de } \\
\text { alimento; Sem } \\
\text { tártaro em boca ou } \\
\text { nas dentaduras }\end{array}$ & $\begin{array}{l}\text { Resíduos de alimento } \\
\text { tártaro ou placa } \\
\text { bacteriana em } 1 \text { a } 2 \\
\text { áreas da boca ou em } \\
\text { pequena áre a da } \\
\text { dentadura } \\
\text { - Mau hálito (halitose) }\end{array}$ & $\begin{array}{l}\text { Restos de alimento ou } \\
\text { tártaro ou placa bacteriana } \\
\text { na maioria das áreas da } \\
\text { boca ou na maior parte das } \\
\text { denta duras } \\
\text { - Mau hálito severo (ha litose) }\end{array}$ & \\
\hline 9) Dor de dente & $\begin{array}{l}\text { Sem sinais } \\
\text { comportamentais, } \\
\text { verbais ou físicos } \\
\text { de dor de dente }\end{array}$ & $\begin{array}{l}\text { S inais verbais ou } \\
\text { comportame ntais de } \\
\text { dor de dente como } \\
\text { caretas, mordidas nos } \\
\text { lábios, falta de apetite, } \\
\text { a gressividade }\end{array}$ & $\begin{array}{l}\text { Sinais físicos como inchaço } \\
\text { facial, absc essos nas } \\
\text { gengivas, dentes que bra dos, } \\
\text { grandes ulce rações, e sinais } \\
\text { verbais ou com portam entais } \\
\text { como caretas, mordidas nos } \\
\text { lábios, falta de apetite, } \\
\text { agressivida de }\end{array}$ & \\
\hline
\end{tabular}


Os resultados da etapa de validação pelos profissionais de enfermagem estão descritos no Quadro 2.

Quadro 2 - Resultados da etapa de validação dos instrumentos pelos profissionais de enfermagem

\begin{tabular}{|c|c|c|c|c|}
\hline & $\begin{array}{l}\mathrm{N}^{\mathrm{o}}(\%) \text { de } \\
\text { pessoas } \\
\text { que Não } \\
\text { Concordam } \\
\text { Fortemente } \\
\end{array}$ & $\begin{array}{c}\mathrm{N}^{\circ}(\%) \text { de } \\
\text { pessoas } \\
\text { que Não } \\
\text { Concordam }\end{array}$ & $\begin{array}{l}\mathrm{N}^{\mathrm{o}}(\%) \mathrm{de} \\
\text { pes soas } \\
\text { que } \\
\text { Concordam }\end{array}$ & $\begin{array}{l}\mathrm{N}^{\mathrm{o}}(\%) \mathrm{de} \\
\text { pessoas } \\
\text { que } \\
\text { Concordam } \\
\text { Fortemente } \\
\end{array}$ \\
\hline $\begin{array}{l}\text { 1. A utilização do Instrumento } \\
\text { melhora } \\
\text { habilidade/capacidade de detectar } \\
\text { dor dental e outros problemas na } \\
\text { boca dos idosos }\end{array}$ & $0(0 \%)$ & $1(4,8 \%)$ & $15(71,4 \%)$ & $5(23,8 \%)$ \\
\hline $\begin{array}{l}\text { 2. Eu me sinto orientado para o uso } \\
\text { do Instrumento de Avaliação da } \\
\text { Condição de SB }\end{array}$ & $1(4,8 \%)$ & $5(23,8 \%)$ & $12(57,1 \%)$ & $3(14,3 \%)$ \\
\hline $\begin{array}{l}\text { 3. Eu teria suporte da instituição } \\
\text { onde atuo para implementar a } \\
\text { utilização do instrumento }\end{array}$ & $1(4,8 \%)$ & $3(14,3 \%)$ & $13(61,9 \%)$ & $4(19 \%)$ \\
\hline $\begin{array}{l}\text { 4. Eu conseguiria completar a } \\
\text { categoria LÁBIOS }\end{array}$ & $1(4,8 \%)$ & $1(4,8 \%)$ & $15(71,4 \%)$ & $4(19 \%)$ \\
\hline $\begin{array}{l}\text { 5. Eu conseguiria completar a } \\
\text { categoria LÍNGUA }\end{array}$ & $1(4,8 \%)$ & $1(4,8 \%)$ & $16(76,1 \%)$ & $3(14,3 \%)$ \\
\hline $\begin{array}{l}\text { 6. Eu conseguiria completar a } \\
\text { categoria GENGIVAS E TECIDOS }\end{array}$ & $1(4,8 \%)$ & $1(4,8 \%)$ & $16(76,1 \%)$ & $3(14,3 \%)$ \\
\hline $\begin{array}{l}\text { 7. Eu conseguiria completar a } \\
\text { categoria SALIVA }\end{array}$ & $2(9,5 \%)$ & $1(4,8 \%)$ & $15(71,4 \%)$ & $3(14,3 \%)$ \\
\hline $\begin{array}{l}\text { 8. Eu conseguiria completar a } \\
\text { categoria DENTES NATURAIS }\end{array}$ & $1(4,8 \%)$ & $2(9,5 \%)$ & $14(66,7 \%)$ & $4(19 \%)$ \\
\hline $\begin{array}{l}\text { 9. Eu conseguiria completar a } \\
\text { categoria DENTADURAS }\end{array}$ & $2(9,5 \%)$ & $1(4,8 \%)$ & $15(71,4 \%)$ & $3(14,3 \%)$ \\
\hline $\begin{array}{l}\text { 10. Eu conseguiria completar a } \\
\text { categoria HIGIENE BUCAL }\end{array}$ & $2(9,5 \%)$ & $1(4,8 \%)$ & $15(71,4 \%)$ & $3(14,3 \%)$ \\
\hline $\begin{array}{l}\text { 11. Eu cons eguiria completar o } \\
\text { instrumento da quanto à } \\
\text { necessidade de encaminhamento } \\
\text { para o cirurgião-dentista. }\end{array}$ & $2(9,5 \%)$ & $3(14,3 \%)$ & $14(66,7 \%)$ & $2(9,5 \%)$ \\
\hline $\begin{array}{l}\text { 12. Eu cons eguiria completar o } \\
\text { instrumento da Avaliação da Saúde } \\
\text { Bucal do Idoso na íntegra }\end{array}$ & $2(9,5 \%)$ & $4(19 \%)$ & $11(52,5 \%)$ & $4(19 \%)$ \\
\hline
\end{tabular}

Observa-se que mais de $95 \%$ dos profissionais consideraram o instrumento útil na detecção de problemas bucais. Mais de $70 \%$ já se sentem orientados a utilizar o instrumento apesar de a sua apresentação inicial, por meio da teleaula, ser relativamente superficial. Aproximadamente $80 \%$ acreditam que a instituição na qual trabalha ofereceria apoio à implementação dos instrumentos.

Já em relação ao exame propriamente dito, aproximadamente $90 \%$ dos participantes se sentiram aptos a proceder o exame bucal nas categorias Lábios, Língua, Gengivas e Tecidos. Em relação às categorias Saliva, Dentes naturais,
Dentaduras e Higiene bucal, mais de $85 \%$ dos participantes da pesquisa consideraram que seriam capazes de completar os exames.

Quando Ihes foi perguntado se seriam capazes de realizar o exame para o encaminhamento para o cirurgiãodentista, 85,7\% dos profissionais da área da enfermagem responderam afirmativamente. Por fim, ao serem questionados se seriam capazes de aplicar o instrumento na íntegra, aproximadamente $71 \%$ responderam afirmativamente.

Em relação aos itens necessários ao aprendizado para utilização do instrumento, a maioria dos participantes 
respondeu: disponibilidade de tempo e capacitação/treinamento prático. Os profissionais acreditam que seria necessário articular com a instituição espaços de tempo para melhor compreender a utilização do instrumento. Além disso, a incorporação gradativa no seu cotidiano de trabalho favoreceria a melhor utilização do instrumento. Assim como citado na literatura ${ }^{1,3,6}$ foi ressaltada a importância da cooperação e conscientização da equipe de profissionais da enfermagem nesta tarefa.

Quanto às barreiras identificadas para a utilização do instrumento, a grande maioria mencionou a resistência por parte dos idosos. Muitas vezes, os idosos não permitem a realização dos procedimentos de exame e higiene bucal ${ }^{2}$ Além disso, a escassez de funcionários, a falta de comprometimento e de conscientização de alguns profissionais, a carência de material e a insuficiência de tempo seriam contrárias a viabilização da aplicação do instrumento na instituição, na opinião dos participantes. Estes achados corroboram fatores que interferem negativamente no cuidado à saúde bucal de idosos institucionalizados ${ }^{12}$. A utilização do "Instrumento de avaliação da saúde bucal para a triagem odontológica" para avaliação das condições de saúde e higiene bucal de idosos residentes em ILPI por profissionais da enfermagem vai depender diretamente da superação destas barreiras.

\section{CONCLUSÕES}

A realização da validação semântica e de conteúdo do instrumento concentrou-se nas correções de ortografia e gramática, na substituição de sinônimos que se adequavam ao contexto brasileiro e aprimoramento da formatação. Observou-se a necessidade de treinamento dos profissionais da área da enfermagem para a correta utilização do instrumento.

A maioria dos profissionais de enfermagem declarou-se orientada e apta a utilizar o ASBTO na sua prática profissional. Entretanto, outras estratégias, associadas ao uso do instrumento, necessitam ser implementadas para auxiliar na superação de algumas barreiras citadas como falta de tempo e resistência dos idosos em receber os exames bucais.

Como produto deste estudo, apresenta-se à comunidade acadêmica o "Instrumento de avaliação da saúde bucal para a triagem odontológica", devidamente traduzido e validado, bem como disponibiliza-se aos profissionais de enfermagem esta importante ferramenta de diagnóstico e encaminhamento dos idosos com relação às demandas de saúde bucal em instituições de longa permanência.

Outro aspecto muito enfatizado pelos experts foi a disposição/formatação do texto do instrumento, o qual foi reorganizado em tópicos específicos, facilitando assim a leitura e compreensão.

\section{REFERÊNCIAS}

1. Moreira MD, Caldas CP. A importância do cuidador no contexto da saúde do idoso. Esc Anna Nery . 2007 set; 11(3): 520-25.

2. Petersen PE, Yamamoto T. Improving the oral health of older people: the approach of the WHO Global Oral Health Programme. Community Dent. Oral Epidemiol. 2005; 33(2): 81-92.

3. Mello ALSF, Erdmann AL. Revelando contradições e incorporando melhores práticas no cuidado à saúde bucal de idosos. Physis 2007 abr; 17(1): 139-56.

4. Davies R, Bedi R, Scully C. ABC of oral health. Oral health care for patients with special needs. BMJ. 2000; 19-26(321): 495-98.

5. Peltola P, Vehkalahti MM, Wuolijoki-Saaristo K. Oral health and treatment needs of the long-term hospitalized elderly. Gerontology 2004; 21 (2): 93-9.

6. Macentee MI. Missing links in oral health care for frail elderly people. J Can Dent Assoc. 2006; 72(5): 421-25.

7 Montal S, Tramini P, Triay JA, Valcarcel J. Oral hygiene and the need for treatment of the dependent institutionalized elderly. Gerodontology 2006 Jun; 23(2): 67-72.

8. Ministério da Saúde (BR). Condições de saúde bucal da população brasileira 2002-2003: resultados principais. Brasília (DF): Coordenação Nacional de Saúde Bucal; 2003.

9. Colussi CF, Freitas SFT. Aspectos epidemiológicos da saúde bucal do idoso no Brasil. Cad Saude Publica. 2002; 18(5): 1313-20.

10 Moreira RS, Nico LS, Tomita NE, Ruiz T. A saúde bucal do idoso brasileiro: revisão sistemática sobre o quadro epidemiológico e acesso aos serviços de saúde bucal. Cad Saude Publica 2005 dez; 21(6): 1665-75.

11. Saliba NA, Moimaz SAS, Marques JAM, Prado RL. Perfil de cuidadores de idosos e percepção sobre saúde bucal. Interface 2007 abr; 11(21): 39-50.

12. Chalmers JM, Levy SM, Buckwalter KC, Ettinger RL, Kambhu PP. Factors influencing nurses' aides' provision of oral care for nursing facility residents. Spec Care Dentist. 1996; 16(2): 71-9.

13. Chalmers JM, Pearson A. A systematic review of oral health assessment by nurses and carers for residents with dementia in residential care facilities. Spec Care Dentist. 2005 Sep/0ct; 25(5): 227-33.

14. Chalmers JM, King PL, Spencer AJ, Wright FA, Carter KD. The oral health assessment tool: validity and reliability. Aust Dent J. 2005 Sep; 50(3): 191-99.

15. Gil-montoya JA, De Mello AL, Cardenas CB, Lopez IG. Oral health protocol for the dependent institutionalized elderly. Geriatr Nurs. 2006 Mar/Apr; 27(2): 95-101. 
16. Chia-hui Chen C, Chyun DA, Li CY, Mccorkle R. A single-item approach to screening elders for oral health assessment. Nurs Res. $2007 \mathrm{Sep} /$ 0ct; 56(5): 332-38.

17. Macentee, M.I. Oral care for successful aging in long-term care. J. Public. Health Dent. 2000; 60(4): 326-29.

18. Vanobbergen JN, De Visschere LM. Factors contributing to the variation in oral hygiene practices and facilities in long-term care institutions for the elderly. Community Dent Health. 2005 Dec; 22(4): 260-5. 